\title{
Protective effect of vitamin E (DL-alpha-tocopherol) against intraventricular haemorrhage in premature babies
}

\author{
MALCOLM L CHISWICK, MARY JOHNSON, CYNTHIA WOODHALL, MAUREEN GOWLAND, \\ JACQUELINE DAVIES, NANCY TONER, DOUGLAS G SIMS
}

\begin{abstract}
Forty four babies, of less than 32 weeks' gestation, were either randomly given $25 \mathrm{mg} / \mathrm{kg}$ vitamin $\mathrm{E}$ (DL- $\alpha-$ tocopherol acetate) intramuscularly after birth (day 0 ) and on days 1, 2, and 3 or served as controls. Frequent real time ultrasound examinations of the brain were made in each baby during the first week and less frequently thereafter. In babies under 32 weeks' gestation the incidence of intraventricular haemorrhage was lower in supplemented babies (18.8\%) compared with the controls (56.3\%). On days $0,1,2$, and 3 median plasma vitamin $E$ concentrations in babies without haemorrhage and in those with subependymal haemorrhage only were similar. Babies with intraventricular haemorrhage had lower median concentrations on day $1(p<0.002)$ and day 2 $(p<0.05)$ compared with those with subependymal haemorrhage and lower concentrations on day $0(p<0.02)$ and day $1(p<0.05)$ compared with those without haemorrhage.

These findings suggest that in premature babies vitamin $E$, an antioxidant, protects endothelial cell membranes from oxidative damage and disruption and limits the magnitude of haemorrhage and its spread from the subependyma into the ventricles.
\end{abstract}

\section{Introduction}

Newborn babies, particularly those born prematurely, have low plasma vitamin $\mathrm{E}$ concentrations compared with older

\footnotetext{
Departments of Neonatal Paediatrics and Radiology, North Western Regional Perinatal Centre, St Mary's Hospital, Manchester M13 0JH

MALCOLM L CHISWICK, MD, FRCP, consultant paediatrician MARY JOHNSON, MB, MRCP, senior registrar in paediatrics CYNTHIA WOODHALL, MB, MRCP, senior registrar in paediatrics MAUREEN GOWLAND, MB, FRCR, consultant radiologist JACQUELINE DAVIES, DCR, DMU, superintendent radiographer NANCY TONER, FIMLS, senior medical laboratory scientific officer DOUGLAS G SIMS, MB, MRCP, consultant paediatrician

Correspondence and reprint requests to: Dr M L Chiswick.
}

infants, children, and adults. ${ }^{2}$ One function of vitamin $E$ is to protect cell membranes against lipid peroxidation ${ }^{3}$; a vitamin $\mathrm{E}$ responsive haemolytic anaemia has been reported in premature babies."

In a study of premature babies designed to assess the appropriate dose of vitamin $E$ required to increase their plasma concentrations to adult values and to reduce the susceptibility of their red blood cells to haemolysis in hydrogen peroxide we made the chance observation that intraventricular haemorrhage was seen less frequently at necropsy in supplemented babies compared with controls. ${ }^{5}$

Intraventricular haemorrhage is the most common finding in the brains of premature babies who die during the first week of life and is probably one of the most important lesions responsible for handicap in surviving babies. ${ }^{6}$ Bleeding usually originates from thin walled capillaries in the highly vascular germinal matrix of the subependymal layer of the brain; the haemorrhage may be confined to the subependymal layer (subependymal haemorrhage) or if extensive may rupture into the ventricles (intraventricular haemorrhage).

We report the preliminary results of a study which examines whether vitamin $\mathrm{E}$ protects against intraventricular haemorrhage diagnosed in living babies by real time ultrasonography.

\section{Patients and methods}

We studied 44 babies who were born at this hospital before 37 weeks' gestation and who weighed less than $1751 \mathrm{~g}$. At birth each baby was randomly allocated to a vitamin $\mathrm{E}$ supplemented $(\mathrm{n}=21)$ or control group $(\mathrm{n}=23)$. We gave $20 \mathrm{mg} / \mathrm{kg}$ of vitamin $\mathrm{E}$ (DL- $\alpha$-tocopherol acetate, Ephynal, Hoffman-La Roche, Basle) intramuscularly on three consecutive days starting within 12 hours of birth (day 0 ) and 24 and 48 hours later (days 1 and 2).

PLASMA VITAMIN E ASSAYS AND HYDROGEN PEROXIDE HAEMOLYSIS TESTS

A $1.5 \mathrm{ml}$ heparinised specimen of venous or arterial blood was sampled from each baby in the control group within 12 hours of birth and from supplemented babies immediately before the first dose of vitamin $\mathrm{E}$ was given. Thereafter, blood specimens were taken from each baby at daily intervals for three days (days 1, 2, and 3). Plasma vitamin $\mathbf{E}$ (total tocopherol) concentration was measured 

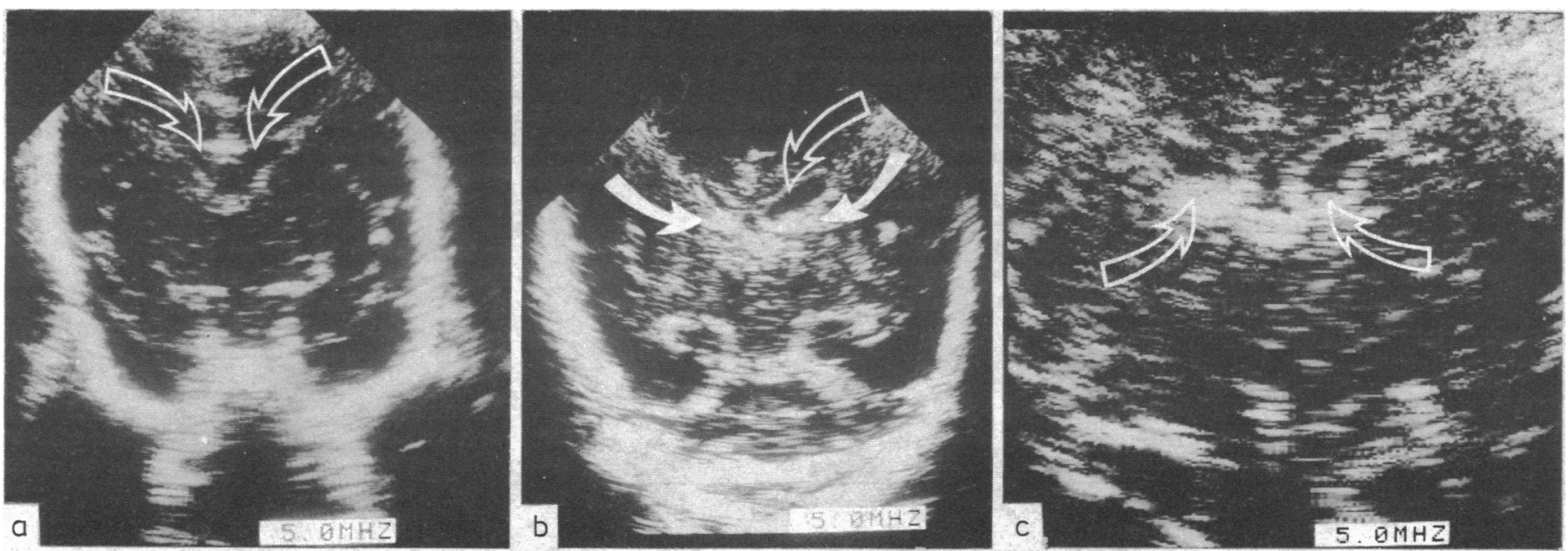

FIG 1-Ultrasound scans of the brain (coronal sections) showing: (a) normal lateral ventricles which appear as slit like cavities (arrows); (b) bilateral subependymal haemorrhages shown as bright echoes (closed arrows) in the floor of the ventricles; both lateral ventricles retain their slit like appearance and the right ventricle (open arrow) is a little larger than the left; and (c) bilateral intraventricular haemorrhage; the bright echoes (arrowed) on this enlarged view represent blood clot inside both ventricles which is more extensive on the left.

on each specimen using a colorimetric method in which ferrous ion produced by the reduction of ferric ion by vitamin $\mathrm{E}$ was used as an index of plasma vitamin $E$ concentration. ${ }^{7}$ The susceptibility of red blood cells to peroxidation was measured on each specimen by the hydrogen peroxide haemolysis test. ${ }^{8}$ Increased susceptibility to haemolysis (that is, a positive result) was indicated if more than $10 \%$ of the baby's red blood cells haemolysed in the hydrogen peroxide solution.

\section{BRAIN SCANS}

Real time ultrasound scans of the brain were carried out by one of us (MG or JD) who did not know the vitamin $E$ status of the babies. The examinations were made with a Technicare autosector scanner (Technicare, Denver, Colorado, USA), model 8100; our method of ultrasound imaging of the brain in the newborn has been described.' Both groups of babies were first scanned within 48 hours of birth (day 0 or day 1) and where possible daily during the first week of life; thereafter babies were examined less often. Scans were graded as showing: no haemorrhage, subependymal haemorrhage only, or intraventricular haemorrhage (fig 1). In babies in whom serial scans showed a change in the grade it was always a deterioration and only the findings on the final scan were reported. All babies with "no haemorrhage" had at least one scan carried out after 72 hours.

\section{CLINICAL INFORMATION}

The gestational age of each baby was calculated from the date of the mother's last menstrual period; when this was uncertain maturity was assessed by examination of the baby. ${ }^{10}$ Clinical information was prospectively recorded and the following definitions were used: perinatal asphyxia-delay in the onset of spontaneous breathing for more than five minutes after birth in the absence of attributable causes other than asphyxia; hyaline membrane disease-respiratory distress presenting within four hours of birth and associated with a chest $x$ ray appearance of diffuse reticular/granular shadowing; and mechanical ventilation-positive pressure ventilation for at least 12 hours.

\section{STATISTICAL ANALYSIS}

The $\chi^{2}$ test or Fisher's test was used to determine the significance of differences in incidence between groups. Student's $t$ test was used to compare mean plasma vitamin $\mathrm{E}$ concentrations between the supplemented and control groups of babies. The non-parametric Mann-Whitney $U$ test was used to compare differences in median plasma vitamin $\mathrm{E}$ concentrations between babies without haemorrhage and those with subependymal or intraventricular haemorrhage.

\section{Results}

Mean plasma vitamin $\mathrm{E}$ concentrations on day 0 in supplemented and control groups were similar. Thereafter, supplemented babies had higher mean plasma vitamin $\mathrm{E}$ concentrations compared with controls $(p<0.001$ ) (fig 2). Throughout the study $52 \cdot 6-88.2 \%$ of babies in the control group had a positive red blood cell haemolysis test. In contrast, the percentage of supplemented babies with a positive test fell from $50.0 \%$ on day 0 to $10.5 \%$ on day 2 and thereafter no supplemented baby had a positive test. Subependymal or

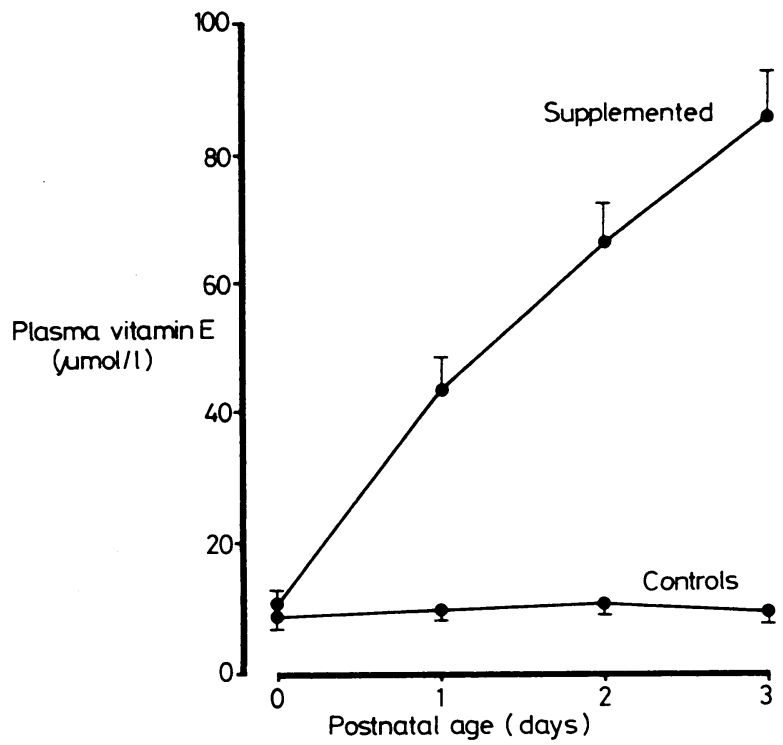

FIG 2-Mean (standard error of mean) plasma vitamin $\mathbf{E}$ concentrations at different postnatal ages in supplemented babies and controls.

intraventricular haemorrhage occurred in 19 of the $44(43.2 \%)$ babies; in 14 the haemorrhage was first observed on days 0,1 , or 2 (within 72 hours of birth). In no baby was haemorrhage first observed after day 4. The incidence of subependymal or intraventricular haemorrhage was similar in the vitamin E supplemented group (nine out of 21, $42.9 \%$ ) and control group (10 out of 23, 43.5\%). Haemorrhage extended into the ventricles, however, in only three of the nine supplemented babies with subependymal or intraventricular haemorrhage, whereas in the control group nine out of 10 had an intraventricular haemorrhage $(p<0.025$, one tailed; $p<0.05$, two tailed). 
All babies with subependymal or intraventricular haemorrhage were of less than 32 weeks' gestation. When only babies of less than 32 weeks' gestation were considered the incidence of intraventricular haemorrhage in the supplemented group (three out of $16,18.8^{\circ}{ }_{0}$ ) was lower compared with the control group (nine out of $16,56.3^{\circ}{ }_{0}$ ) ( $p<0.05$, one tailed; $p<0 \cdot 1$, two tailed). Two supplemented babies died and neither had intraventricular haemorrhage; both of the babies in the control group who died had intraventricular haemorrhage. Gestational age and birthweight indices and the incidence of certain risk factors for intraventricular haemorrhage were similar in supplemented and control groups in all babies of less than 32 weeks' gestation and in only those who had subependymal or intraventricular haemorrhage (table).

Birthweights, gestational ages, and risk factors for intraventricular haemorrhage in all babies of $<32$ weeks' gestation and in those with subependymal or intraventricular haemorrhage

\begin{tabular}{|c|c|c|c|c|}
\hline & \multicolumn{2}{|c|}{ All babies $(<32 \mathrm{w})$} & \multicolumn{2}{|c|}{$\begin{array}{l}\text { Subependymal or } \\
\text { intraventricular } \\
\text { haemorrhage }\end{array}$} \\
\hline & Supplemented & Control & Supplemented & Control \\
\hline \multicolumn{5}{|l|}{ Birthweight (g) } \\
\hline $\begin{array}{l}\text { Mean }(\mathrm{SD}) \\
\text { Median } \\
\text { Range }\end{array}$ & $\begin{array}{r}1349(254) \\
1445 \\
900-1700\end{array}$ & $\begin{array}{l}1273(177) \\
1275 \\
1050-1750\end{array}$ & $\begin{array}{r}1319(269) \\
1440 \\
900-1620\end{array}$ & $\begin{array}{l}1263(216) \\
1225 \\
1050-1750\end{array}$ \\
\hline \multicolumn{5}{|l|}{ Gestational age (weeks) } \\
\hline $\begin{array}{l}\text { Mean (SD) } \\
\text { Median } \\
\text { Range }\end{array}$ & $\begin{array}{l}29 \cdot 3(1 \cdot 8) \\
29 \\
25-31\end{array}$ & $\begin{array}{l}29 \cdot 4(1 \cdot 2) \\
29 \\
27-31\end{array}$ & $\begin{array}{l}29 \cdot 1(2 \cdot 1) \\
30 \\
25-31\end{array}$ & $\begin{array}{l}29 \cdot 4(1 \cdot 1) \\
29 \\
28-31\end{array}$ \\
\hline $\begin{array}{l}\text { No of babies with: } \\
\text { Hyaline membrane } \\
\text { disease } \\
\text { Mechanical ventilation } \\
\text { Pneumothorax } \\
\text { Perinatal asphyxia }\end{array}$ & $\begin{array}{l}5 \\
5 \\
0 \\
3\end{array}$ & $\begin{array}{l}5 \\
6 \\
1 \\
3\end{array}$ & $\begin{array}{l}4 \\
4 \\
0 \\
1\end{array}$ & $\begin{array}{l}4 \\
5 \\
1 \\
1\end{array}$ \\
\hline
\end{tabular}

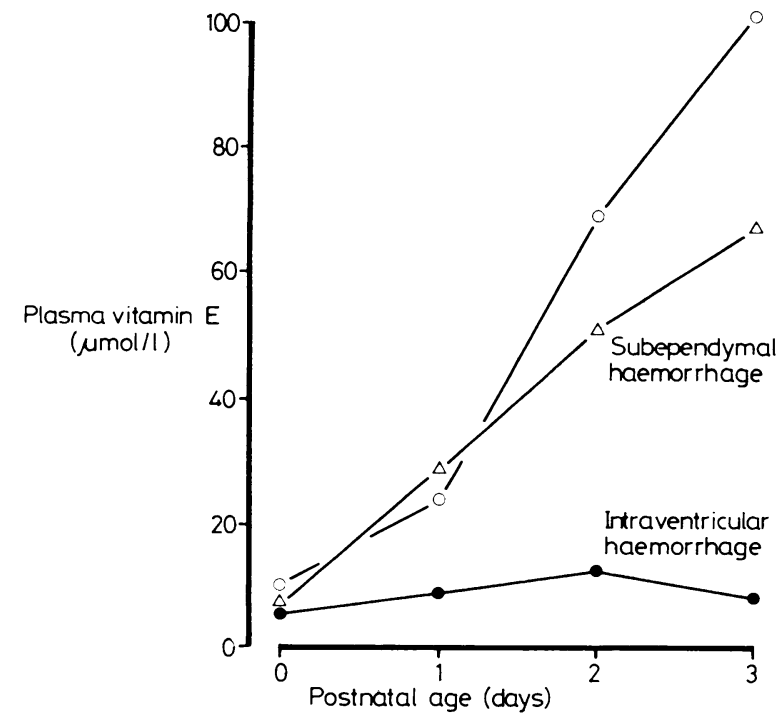

FIG 3-Median plasma vitamin $\mathrm{E}$ concentrations at different postnatal ages in babies of $<32$ weeks' gestation without any haemorrhage $(0)$ with subependymal haemorrhage only $(\triangle)$, and with intraventricular haemorrhage (O). Significance tests (Mann-Whitney U, two tailed): Subependymal $v$ intraventricular haemorrhage $-\mathrm{p}<0.002$ day $1, \mathrm{p}<0.05$ day 2 ; no haemorrhage $v$ intraventricular haemorrhage $-p<0.02$ day $0, p<0.05$ day 1 ; no haemorrhage + subependymal $v$ intraventricular haemorrhage $-\mathrm{p}<0.03$ day $0, \mathrm{p}<0.02$ day $1, \mathrm{p}<0.05$ day $2, \mathrm{p}<0.05$ day 3 .

When babies of less than 32 weeks' gestation were considered together (supplemented and control groups) then throughout the study the median plasma vitamin $\mathrm{E}$ concentrations of those without any haemorrhage were similar to the corresponding values in babies with subependymal haemorrhage only. In contrast, babies with intraventricular haemorrhage had significantly lower median plasma vitamin $\mathrm{E}$ concentrations on days 1 and 2 compared with those who had subependymal haemorrhage only and significantly lower values on days 0,1 , and 2 compared with babies who did not have any

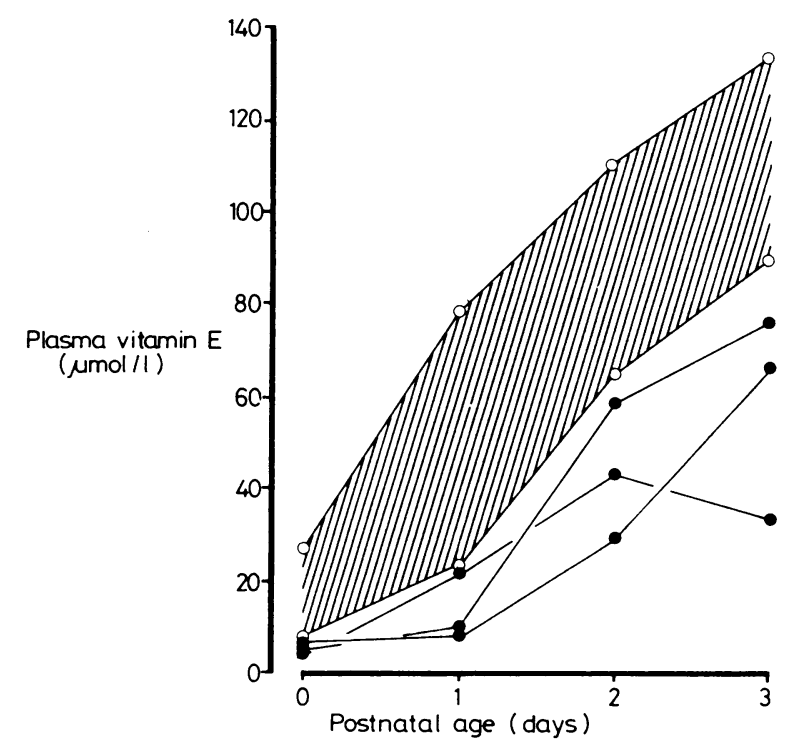

FIG 4-Range of plasma vitamin $\mathrm{E}$ concentrations at different postnatal ages in supplemented babies of $<32$ weeks' gestation without any haemorrhage (shaded). Plasma vitamin $\mathrm{E}$ concentrations of the three supplemented babies with intraventricular haemorrhage are shown (O).

haemorrhage (fig 3). Throughout the study each of the three babies who had an intraventricular haemorrhage despite vitamin supplementation had plasma vitamin $\mathrm{E}$ concentrations below the range observed in supplemented babies who had no haemorrhage (fig 4).

\section{Discussion}

The lower limit of normal for plasma vitamin $\mathrm{E}$ concentrations in older infants and adults is usually given as $11.6 \mu \mathrm{mol} / 1$ $(0.5 \mathrm{mg} / 100 \mathrm{ml}) .{ }^{11}$ Our findings confirm that at birth the mean plasma vitamin $\mathrm{E}$ concentration of premature babies is low and their red blood cells have an increased susceptibility to haemolysis in a dilute solution of hydrogen peroxide. The rise in mean plasma vitamin $\mathrm{E}$ concentration and reduced susceptibility of red blood cells to hydrogen peroxide haemolysis were benefits observed only in supplemented babies.

The overall incidence of subependymal or intraventricular haemorrhage of $43.2 \%$ in our study and the timing of haemorrhages, with most $(73.7 \%$ ) occurring in the first 72 hours, are entirely in keeping with observations made by other investigators. $^{12-15}$ Several findings in our study suggest that while vitamin $\mathrm{E}$ does not reduce the incidence of subependymal haemorrhage it does protect against extension of haemorrhage into the ventricles in babies born very prematurely. Firstly, supplemented babies had a lower incidence of intraventricular haemorrhage compared with controls. Secondly, babies with intraventricular haemorrhage had lower plasma vitamin $\mathrm{E}$ concentrations compared with those who had no haemorrhage or subependymal haemorrhage only. Thirdly, the three babies who had intraventricular haemorrhage despite supplementation were the only ones whose plasma vitamin $\mathrm{E}$ concentrations were below the range observed in supplemented babies who did not have any haemorrhage.

The pathological anatomy of subependymal and intraventricular haemorrhage in relation to the developing central nervous system microcirculation has been reviewed by Pape and Wigglesworth. ${ }^{6}$ Apart from prematurity aetiological factors include hypoxaemia, ${ }^{6}$ hypercapnoea, ${ }^{6} 1516$ intravenous sodium bicar- 
bonate treatment, ${ }^{1718}$ mechanical ventilation, ${ }^{6}{ }^{16}$ and pneumothorax..$^{19} 20$ It is, therefore, not surprising that babies with hyaline membrane disease are vulnerable. An increase in cerebral blood flow is thought to be a key factor in the train of events that culminate in subependymal or intraventricular haemorrhage. ${ }^{6}$ The factors that promote extension of haemorrhage from the subependymal layer into the ventricles are not understood. It is possible that a pressure differential across the ependyma plays a part. More important is the observation that extensive subependymal bleeding causes venous infarction within the germinal matrix ${ }^{6}$; it is possible that extension of haemorrhage into the ventricles is simply the result of germinal matrix and ependymal destruction.

We propose a new theory that oxidative damage to capillary endothelial membranes of the subependymal layer contributes to the pathogenesis of subependymal and intraventricular haemorrhage in premature babies. We suggest that vitamin $\mathrm{E}$ protects endothelial membranes, limits the magnitude of haemorrhage in the subependymal layer, and hence reduces the risk of extension of haemorrhage into the ventricles. We did not observe a relation between intraventricular haemorrhage and susceptibility to hydrogen peroxide haemolysis but protection of endothelial membranes by vitamin $\mathrm{E}$ would not necessarily be reflected by the ability of red blood cell membranes to withstand oxidative stresses.

The fact that intraventricular haemorrhage is relatively uncommon in stillborn babies ${ }^{21}$ is pertinent to our hypothesis. The fetal arterial $\mathrm{Po}_{2}$ is normally only $\approx 3.33 \mathrm{kPa}(\approx 25 \mathrm{~mm} \mathrm{Hg})$ and this low level might prevent oxidative damage to the endothelial membranes of the germinal matrix occurring in utero. Thus it is possible that while acute hypoxia encourages subependymal or intraventricular haemorrhage by increasing cerebral blood flow chronic hypoxia reduces oxidative stresses on endothelial walls. Indeed, paediatricians are familiar with certain premature babies with respiratory distress and persistent pulmonary hypertension who remain cyanosed until death at 24 to 48 hours and who surprisingly do not have intraventricular haemorrhage at necropsy.

The idea that vitamin E reduces capillary fragility is not a new one. ${ }^{22-24}$ Over 30 years ago Minkowski, on the basis of maternal supplementation experiments, suggested that the vitamin protected against "hémorragies cérébro-méningées du prématuré" -an idea that was not widely accepted. ${ }^{25}$ Further support for our hypothesis comes from certain vitamin $\mathrm{E}$ deficiency diseases in animals. In nutritional encephalomalacia in chicks, ${ }^{26}$ although the cerebellum bears the brunt of the pathology, the cerebral hemispheres are not spared and endothelial cell changes culminating in haemorrhage are a prominent feature. Swelling and fragmentation of the endothelial cells of the central nervous system microcirculation are observed by electron microscopy in vitamin $\mathrm{E}$ deficient chicks. ${ }^{27}$ Of special interest is a vitamin $\mathrm{E}$ responsive disorder in hamsters known as spontaneous haemorrhagic necrosis of the central nervous system, in which the initial haemorrhagic lesions do indeed involve the subependymal vasculature and progress to intraventricular haemorrhage. ${ }^{28}$

It should not go unnoticed that in our study on day 0 , even before vitamin supplements were given, babies who suffered intraventricular haemorrhage had a marginally but significantly lower mean plasma vitamin $\mathrm{E}$ concentration compared with babies without intraventricular haemorrhage. We cannot rule out the possibility that some babies suffered subependymal or intraventricular haemorrhage before the first dose of vitamin $\mathrm{E}$ was given. Although there is a "transport barrier" to the passage of vitamin $\mathrm{E}$ from mother to fetus, ${ }^{29}$ maternal supplementation during premature labour should be explored because it might benefit babies by marginally increasing their plasma concentrations above a threshold that protects endothelial cell membranes.

We thank Hofimann-La Roche for the supply of Ephynal and Mrs M O'Donnell for secretarial help.

\section{References}

${ }^{1}$ Moyer WT. Vitamin E levels in term and premature newborn infants Pediatrics 1950;6:893-6.

2 Wright SW, Filer LJ Jr, Mason KE. Vitamin E blood levels in premature and full term infants. Pediatrics $1951 ; 7: 386-93$.

${ }^{3}$ McCay PB, King MM. Vitamin E: its role as a biologic free radical scavenger and its relationship to the microsomal mixed-function oxidase system. In: Machlin LJ, ed. Vitamin E, a comprehensive treatise. New York, Basle: Marcel Dekker Inc, 1980:289-317.

4 Oski FA, Barness LA. Vitamin E deficiency: a previously unrecognised cause of haemolytic anaemia in the premature infant. $\mathcal{F}$ Pediatr 1967; 70:211-20.

5 Chiswick ML, Wynn J, Toner N. Vitamin E and intraventricular hemorrhage in the newborn. Ann NY Acad Sci $1982 ; 393: 109-18$.

- Pape KE, Wigglesworth JS. Haemorrhage, ischaemia and the perinatal brain. Spastics International Medical Publications. London: William Heinemann Medical Books. Philadelphia: JB Lippincott Co, 1979.

${ }^{7}$ Martinek RG. Method for determination of vitamin E (total tocopherols) in serum. Clin Chem 1964;10:1078-86.

${ }^{8}$ Gordon HH, Nitowsky HM, Cornblath M. Studies of tocopherol deficiency in infants and children. I Hemolysis of erythrocytes in hydrogen peroxide. Am f Dis Child 1955;90:669-81.

${ }^{9}$ Gowland M, Chiswick, ML. Ultrasound imaging of the brain in the newborn. In: Chiswick ML, ed. Recent advances in perinatal medicine. Vol 1. Edinburgh, London: Churchill Livingstone, 1983:209-29.

${ }^{10}$ Dubowitz LMS, Dubowitz V, Goldberg C. Clinical assessment of gestational age in the newborn infant. $\mathcal{F}$ Pediatr $1970 ; 77: 1-10$.

11 Farrell PM. Deficiency states, pharmacological effects and nutrient requirements. In: Machlin LJ, ed. Vitamin E, a comprehensive treatise. New York, Basle: Marcel Dekker Inc, 1980:524.

12 Papile LA, Burstein J, Burstein R, Koffler H. Incidence and evolution of subependymal and intraventricular haemorrhage: a study of infants with birthweights less than 1500 g. F Pediatr 1978;92:529-34.

13 Ahmann PA, Lazzara A, Dykes FD, Brann AW Jr, Shwartz JF. Intracranial hemorrhage in the high-risk preterm infant: incidence and outcome. Ann Neurol 1980;7:118-24.

${ }^{14}$ Levene MI, Wigglesworth JS, Dubowitz V. Cerebral structure and intraventricular haemorrhage in the neonate: a real time ultrasound study. Arch Dis Child $1981 ; 56: 416-24$.

15 Cooke RWI. Factors associated with periventricular haemorrhage in very low birthweight infants. Arch Dis Child 1981 ;56:425-31.

16 Levene MI, Fawer C-L, Lamont RF. Risk factors in the development of intraventricular haemorrhage in the preterm neonate. Arch Dis Child $1982 ; 57: 410-7$.

17 Simmons MA, Adcock EW, Bard H, Battaglia FC. Hypernatraemia and intracranial haemorrhage in neonates. $N$ Engl f Med 1974;291:6-10.

18 Papile L-A, Burstein J, Burstein R, Koffler H, Koops B. Relationship of intravenous sodium bicarbonate infusion and cerebral intraventricular haemorrhage. $\mathcal{F}$ Pediatr 1978;93:834-6.

19 Lipscomb AP, Thorburn R, Reynolds EOR, et al. Pneumothorax and cerebral haemorrhage in preterm infants. Lancet 1981 ; :414-6.

${ }^{20}$ Hill A, Perlman JM, Volpe JJ. The relationship of pneumothorax to the occurrence of intraventricular haemorrhage in the premature newborn. Pediatrics $1982 ; 69: 144-9$.

${ }^{21}$ Harcke HT, Naeye RL, Storch A, Blanc WA. Perinatal cerebral intra ventricular hemorrhage. $\mathcal{F}$ Pediatr 1972;80:37-42.

${ }^{22}$ Naegeli Th. Beeinflussung der kapillarwand durch vitamin E. Aerztliche Forschung $1952 ; 6: 247-9$.

23 Gerloczy F, Lancos F, Szabo J. Wirkung des vitamin E auf die kapillarresistenz bei purpura im kindesalter. Acta Paediatr Acad Sci Hung $1966 ; 7: 363-7$

¿4 Fujii $\mathrm{T}$. The clinical effects of vitamin $\mathrm{E}$ on purpuras due to vascular defects. $\mathcal{F}$ Vitaminol $1972 ; 18: 125-30$

${ }_{25}$ Minkowski A. La resistance vasculaire du nouveau-né et la prevention des hémorragies cérébro-méningées du prématuré. Ann Paediatr 1950; 174:80-6.

26 Pappenheimer AM, Goettsch M. A cerebellar disorder in chicks apparently of nutritional origin. $\mathcal{F}$ Exper Med 1931;53:11-26.

27 Yu WA, Yu MC, Young PA. Ultrastructural changes in the cerebrovascular endothelium induced by a diet high in linoleic acid and deficient in vitamin E. Exp Mol Pathol 1974;21:289-99.

${ }^{28}$ Keeler RF, Young S. Role of vitamin $\mathrm{E}$ in the etiology of spontaneous hemorrhagic necrosis of the central nervous system of fetal hamsters. Teratology $1979 ; 20: 127-32$.

${ }^{29}$ Leonard PJ, Doyle E, Harrington W. Levels of vitamin E in the plasm of newborn infants and of mothers. Am f Clin Nutr $1972 ; 25: 480-4$. 